\title{
Optimization of the chin bar of a composite-shell helmet to mitigate the upper neck force
}

\author{
S. Farajzadeh Khosroshahi ${ }^{1}$, U. Galvanetto ${ }^{1}$, M. Ghajari ${ }^{2}$ \\ 1 Department of Industrial Engineering, University of Padova, Padova, Italy \\ 2 Dyson School of Design Engineering, Imperial College London, South Kensington Campus, London, UK
}

\begin{abstract}
The chin bar of motorcycle full-face helmets is the most likely region of the helmet to sustain impacts during accidents, with a large percentage of these impacts leading to basilar skull fracture. Currently, helmet chin bars are designed to mitigate the peak acceleration at the centre of gravity of isolated headforms, as required by standards, but they are not designed to mitigate the neck force, which is probably the cause of basilar skull fracture, a type of head injury that can lead to fatalities. Here we test whether it is possible to increase the protection of helmet chin bars while meeting standard requirements. Fibre-reinforced composite shells are commonly used in helmets due to their lightweight and energy absorption characteristics. We optimize the ply orientation of a chin bar made of fibre-reinforced composite layers for reduction of the neck force in a dummy model using a computational approach. We use the finite element model of a human head/neck surrogate and measure the neck axial force, which has been shown to be correlated with the risk of basilar skull fracture. The results show that by varying the orientation of the chin bar plies, thus keeping the helmet mass constant, the neck axial force can be reduced by approximately $30 \%$ while ensuring that the helmet complies with the impact attenuation requirements prescribed in helmet standards.
\end{abstract}

\section{Keywords}

Helmet, chin bar, upper neck force.

\section{Notations}

E Modulus of elasticity

$\rho \quad$ Density

$v \quad$ Poisson's ratio

$\sigma_{y} \quad$ Yield stress

$E_{L} \quad$ Longitudinal elastic modulus

$E_{T} \quad$ Transverse elastic modulus

$G_{L T} \quad$ Shear modulus 
$v_{L T} \quad$ Major Poisson's ratio

$S_{u c, L} \quad$ Longitudinal compressive strength

$S_{u c, T} \quad$ Transverse compressive strength

$S_{u t, L} \quad$ Longitudinal tensile strength

$S_{u t, T} \quad$ Transverse tensile strength

$\varepsilon_{u c, L} \quad$ Ultimate longitudinal compressive strain

$\varepsilon_{u c, T} \quad$ Ultimate transverse compressive strain

$\varepsilon_{u t, L} \quad$ Ultimate longitudinal tensile strain

$\varepsilon_{u t, T} \quad$ Ultimate transverse tensile strain

$\tau_{u} \quad$ Shear strength

$\gamma_{u} \quad$ Ultimate shear strain

\section{Introduction}

Over thirty thousand people die and more than 1.5 million people are injured every year in Europe because of road traffic accidents [1]. Motorcyclists are among the most vulnerable road users. Accident data analysis shows that motorcycle riders are in peril of death almost thirty times more than car occupants in road traffic accidents, with head injury being the leading cause of death and disability in motorcyclists [2-4]. Motorcycle helmets are the most effective item of protective equipment for head protection [5] and their design can be further improved in order to reduce the risk of head injuries.

There have been several experimental and computational studies on motorcycle helmets since the middle of the last century [5]. The majority of these studies have addressed protection against brain injuries [5] and a few have addressed other types of injury, such as neck injury or basilar skull fracture [6-9]. Richter et al. [10] studied mechanisms of brain injury in helmeted motorcyclists, and Liu et al. [11] and Abbas et al. [12] showed that helmets can reduce the severity of brain injuries. Other researchers have developed computational models of brain injury and used them to study the protection offered by helmets [13-15]. Computational models of helmets have also been developed and used to improve helmet design [16,17], to understand the performance of helmets in realistic impact conditions [18] and to investigate the effects of the head/neck interaction on impact performance of the helmet and head [18,19]. Some experimental studies have also been carried out in order to improve the head protection capability of motorcycle helmets. Caserta et al. [20] studied the effect of using the honeycomb material in the liner and Coelho et al. [21] assessed the feasibility of using a composite liner made of EPS and cork, with the objective to reduce head linear acceleration, which is thought to be related to the risk of brain injury and used in helmet standards as a pass/fail criterion.

Basilar skull fracture (BSF) is one of the most common type of skull fractures sustained by motorcycle riders [22-25]. A clinical survey by Chee and Ali [25] revealed that $50 \%$ of patients suffering from BSF were motorcyclists. Dowdell et al. [22] studied 200 accidents involving helmeted motorcyclists and found that the chin bar of full-face helmets has the highest probability of impacts during accidents. According to this 
study, almost $50 \%$ of the severe impacts took place on the front of the helmet, involving the chin bar, and $40 \%$ of these impacts led to BSF. In a similar work, Whyte et al. [23] studied 47 cases of fatal motorcycle accidents and found that BSF was the most frequent type of head injury (31 cases), and interestingly in 15 cases suffering from BSF, there was no injury at the impact site. Another in depth injury analysis of nonfatal motorcycle accidents showed that almost $69 \%$ of cranium fractures took place at the base of skull [24].

The base of the skull is its weakest region [26]. Any fracture occurring in this region or propagating to this region is called basilar skull fracture [27]. BSF can be caused by direct impacts at the base of the skull or by remote impacts $[28,29]$, such as craniofacial impacts, which frequently occur in motorcycle accidents [22] and can lead to BSF [30,31]. Cooter and David [30] postulated that the impact load due to the blows on the full-face helmet's chin bar can be transmitted to the base of skull via the chin strap and lead to BSF. Fracture at the skull base can lead to fatal injuries, such as damage to the carotid artery [32] or basilar artery thrombosis [33]. The latter injury can occur even when brain or cervical injuries are mild [34,35].

According to clinical surveys, both compressive and tensile loading might cause BSF [36,37]. In case of compressive loading like cranial vault impact, it was thought that the cranium, due to its smooth curvature, could withstand the impact load and transmit the load to the base of skull, leading to BSF. In case of tensile loading, it was hypothesized that since the strength of the atlanto-occipital ligaments and musculature is higher than occipital bone's the tensile loading like in case of hyperextension results in the skull base fracture instead of separation at the spine-skull junction [38,39]. McElhanney et al. [40] carried out an experimental study on cadavers to better understand the mechanisms of BSF. Three different types of loading were used in their work. The first type was direct loading of the mandible by dropping the head with mandible hitting a rigid anvil. The aim was to evaluate the effect of the load transferred through the temporomandibular joint to the base of the skull. In the second series of experiments, an un-embalmed head was subjected to a direct temporomandibular loading in conjunction with tensile neck loading. In the third series of tests, an intact head-neck, with a simulated torso mass, was dropped onto a rigid anvil in order to assess the effect of the compressive neck load on the skull base. It was found that the neck tensile load at the base of the skull was the most probable loading condition that can produce BSF. They reported peak neck forces which led to ring basilar skull fractures from $2.74 \mathrm{KN}$ to $4.72 \mathrm{KN}$. Therefore, we used the neck tensile load at the upper neck as the indicator of BSF in the present study.

There are only two helmet standards that require testing helmet chin bars, ECE22.05 [41] and Snell M2015 [42]. These standards assess the chin bar of full face helmets by replicating a probable impact on the chin bar during an accident as a direct blow to the centre of the chin bar, and their pass/fail criteria are based on the risk of brain injury only. Due to the high probability of basilar skull fracture related to chin bar impacts in motorcycle crashes and the lack of test methods that address chin bar design for BSF mitigation, in this work we use a human head/neck surrogate, Hybrid III, to test whether it is possible to decrease the upper neck tensile force, the indicator of BSF, by altering the ply orientation of a composite chin bar, while meeting requirements of standards. This work is the first step of an attempt to consider the neck tensile load in the design process of the helmet chin bar by means of computational methods.

The paper is organized as follows. In section 2, the finite element models of the composite shell helmet and the head/neck assembly are described. The design variables, objective function and the search algorithm are also described in this section. In section 3, the results, including the optimal chin bar lay-up, 
are presented and the mitigation mechanisms are discussed. Finally, section 4 provides some concluding remarks with directions for future work.

\section{Methods}

We used finite element models of a full-face composite-shell motorcycle helmet, the $50^{\text {th }}$ percentile male hybrid III dummy and the medium size ISO headform for this study. Using a computational approach enabled us to perform several iterations within the design space to search for the optimal solution. In the following sections, the models, impact conditions and search algorithm have been described.

\subsection{Helmet FE model}

The finite element model of the AGV-T2 helmet (Figure 1), size 58 [43] manufactured by Dainese S.p.A (a partner of the MOTORIST EU network) was used for this study. The main parts of the helmet, which are involved in energy absorption, are the composite shell and the foam liner. 4-node quadrilateral shell elements were used to generate the FE model of the composite shell and 4-node tetrahedral solid elements for the liner discretization as shown in Figure 1. The chin strap was modeled using 4-node quadrilateral shell elements with a Young's modulus of $1 \mathrm{GPa}$ and a Poisson's ratio of 0.3 [44].

The liner was composed of four sub-parts, i.e. main, top, chin and cheek liners (Figure 1), each made of expanded polystyrene (EPS) with a different density (Table 1 and Figure 2). The Crushable Foam material model (MAT_063 from LS-Dyna material library) was used to model the foam parts $[43,45]$. This model requires the definition of the compressive stress-strain curve. This curve was obtained using semiempirical equations provided in [46] and explained in $[18,19,47]$.

The shell of the helmet is made of composite laminates with different layups in different regions of the helmet (Figure 3). Test coupons were cut from different regions of the helmet in order to identify the ply layups and characterize their mechanical properties [44]. Table 2 and Figure 3 show different types of lamina used in the shell and the layups in different regions of the shell, respectively. In the FE model, Laminated Composite Fabric material model (MAT_058 from LS-Dyna material library) was used for the shell $[43,45]$ with the material constants presented in Table 3.

MAT_058 has the capability of predicting the failure initiation and evolution in composite plies according to the following constitutive equation $[48,49]$ :

$\left[\begin{array}{c}\sigma_{L} \\ \sigma_{T} \\ \tau\end{array}\right]=\frac{1}{C}\left[\begin{array}{ccc}\left(1-\omega_{L}\right) E_{L} & \left(1-\omega_{L}\right)\left(1-\omega_{T}\right) v_{T L} E_{T} & 0 \\ \left(1-\omega_{L}\right)\left(1-\omega_{T}\right) v_{L T} E_{L} & \left(1-\omega_{T}\right) E_{T} & 0 \\ 0 & 0 & C\left(1-\omega_{L T}\right) G_{L T}\end{array}\right] \times\left[\begin{array}{c}\varepsilon_{L} \\ \varepsilon_{T} \\ \gamma\end{array}\right] \quad$ (Equation 1)

$C=1-\left(1-\omega_{L}\right)\left(1-\omega_{T}\right) v_{L T} v_{T L}$

(Equation 2)

where $\sigma, \varepsilon, \tau$ and $\gamma$ are normal stress, normal strain, shear stress and shear strain respectively. The subscripts $L$ and $T$ indicate longitudinal and transverse directions. $\omega$ is the damage function which is defined as follows [49]:

$\omega=1-\frac{\alpha S_{u t, u c}}{E_{L, T} \varepsilon}$

(Equation 3)

where $\alpha$ isthe ratio of the limiting stress to the peak stress $[49,50]$ and has been considered equal to 0.1 $[43,44]$ for the present study. In this material model when an element fails, its moduli degrade to near 
zero but the element will not be deleted in order to avoid instability problems at the interfaces with other parts, like liner and anvil in the present work $[44,45]$.

The contact between the shell and the main liner, cheek and chin liner was defined using Automatic Surface to Surface algorithm [45]. The same contact card was used in order to define the contact between the top liner and the main liner, the chick foams and the main liner and between the chick and the chin liners. The friction coefficient at shell/headform, shell/liners interfaces and between different parts of the liner was set to 0.5 and the friction coefficients at the interface of the helmet and anvil (cylindrical impactor) was set to 0.23 [19]. The total mass of the helmet was $0.96 \mathrm{~kg}$ excluding the visor's mass and the mass of the comfort foams.

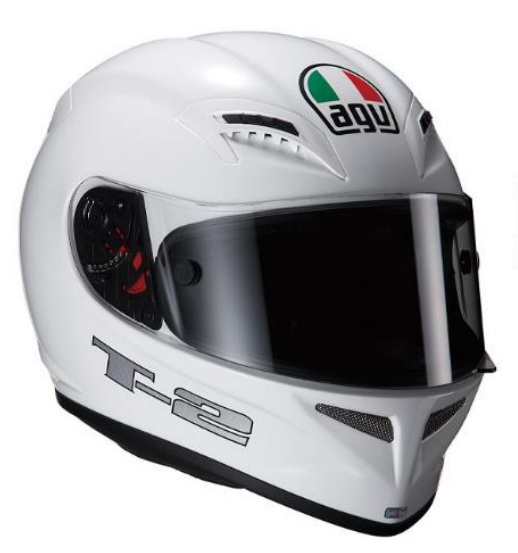

(a)

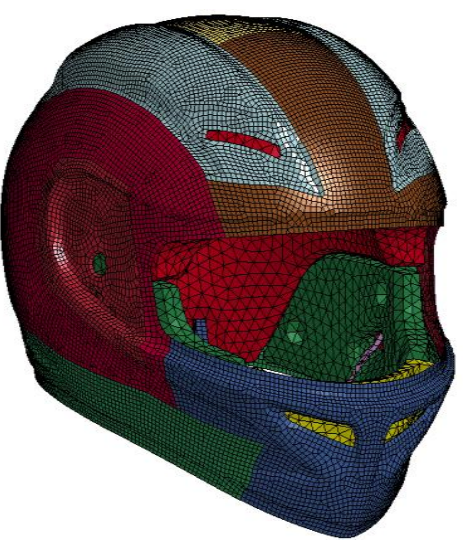

(b)

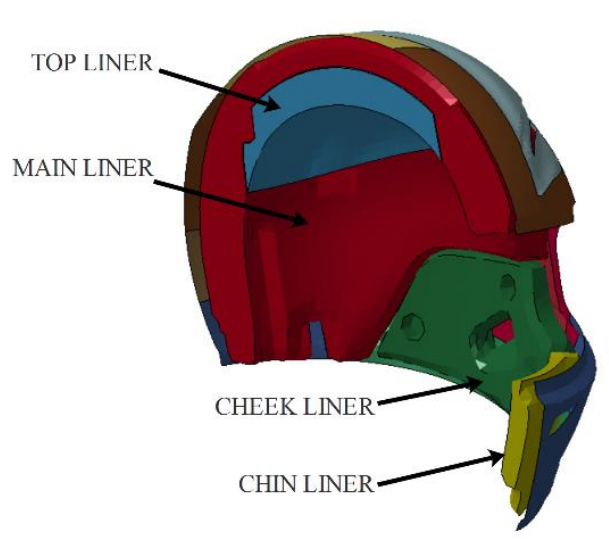

(c)

Figure 1 a: AGV T2 Helmet, b: FE model of the helmet, c: foam liners (some parts of the helmet are not shown).

Table 1 Material properties of foam parts [44].

\begin{tabular}{lllll}
\hline Part & $\rho\left(\mathrm{kg} / \mathrm{m}^{3}\right)$ & $E(\mathrm{MPa})$ & $v$ & $\sigma_{y}(\mathrm{MPa})$ \\
\hline EPS; top liner & 20 & 2.9 & 0.01 & 0.13 \\
EPS; main liner & 40 & 10.6 & 0.01 & 0.36 \\
EPS; cheek and chin liners & 60 & 23.2 & 0.01 & 0.66 \\
\hline
\end{tabular}




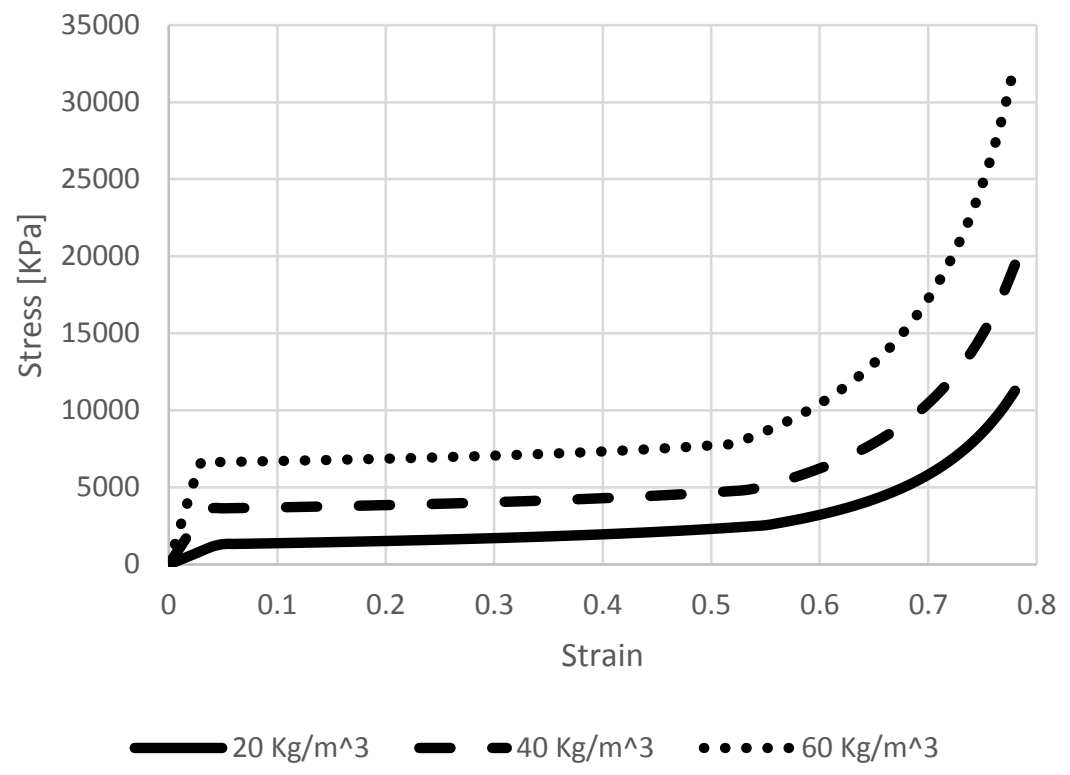

Figure 2 Compressive stress-strain curves used for foam parts [44] .

Table 2 Shell Materials [44].

\begin{tabular}{lllll}
\hline Material NO. & Resin & Fibre & Lamina Type & Symbol \\
\hline 1 & & Carbon & Unidirectional & C \\
2 & & & Unidirectional & G \\
3 & Epoxy & Glass & Twill Weave & TW,G \\
4 & & & Plain Weave & PL,G \\
5 & & Hybrid (Kevlar/carbon) & Unidirectional & H \\
\hline
\end{tabular}

The finite element model of the helmet was previously used to simulate the impact attenuation test of the ECE 22.05 standard [44], whole-body drop tests using a Hybrid III dummy [19,44] and oblique impacts using a Hybrid II headform [51]. The head linear and rotational accelerations and the neck forces predicted in these simulations were in good agreement with the experimental data. 


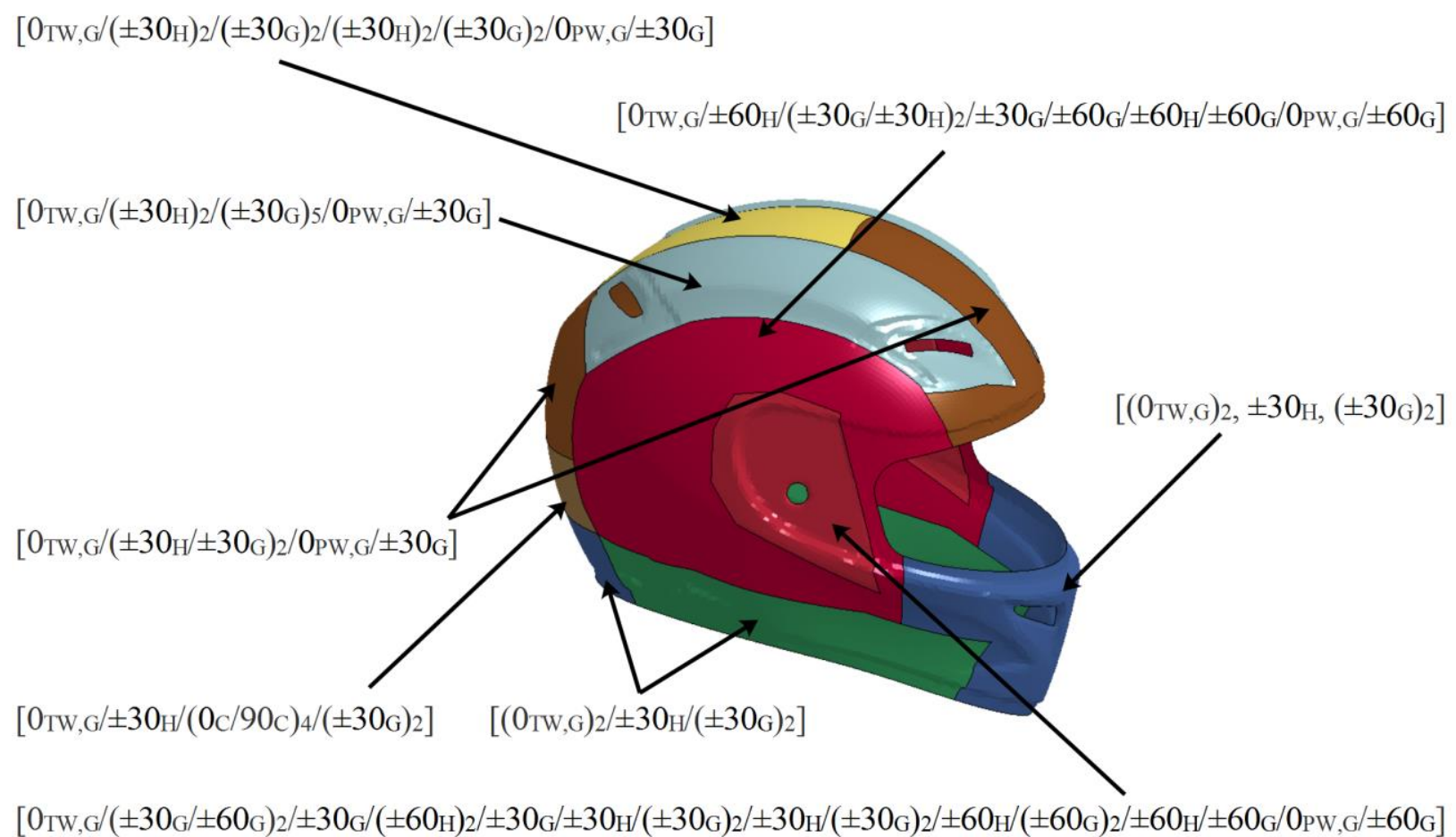

Figure 3 Ply layup for different parts of the shell [44].

The stiffness and energy absorption capability of composite laminates are functions of fibre orientations in each lamina [52,53]. Hence, by carefully selecting ply orientations of the composite chin bar of the helmet, thus keeping the mass of the helmet constant, it may be possible to reduce the force transmitted to the neck during chin impacts. The chin bar of the AGV-T2 helmet has a $\left[\left(0_{\mathrm{TW}, \mathrm{G}}\right)_{2}, \pm 30_{\mathrm{H}},\left( \pm 30_{\mathrm{G}}\right)_{2}\right]$ configuration and is made of pairs of three different plies: glass/epoxy twill weave, unidirectional Kevlar/carbon/epoxy hybrid and unidirectional glass epoxy (Figure 3), where TW, G is the external ply (see Figure 4). The orientation of ply pairs, i.e. $\theta_{1}, \theta_{2}$ and $\theta_{3}$ shown in Figure 4 , were the design variables in this study.

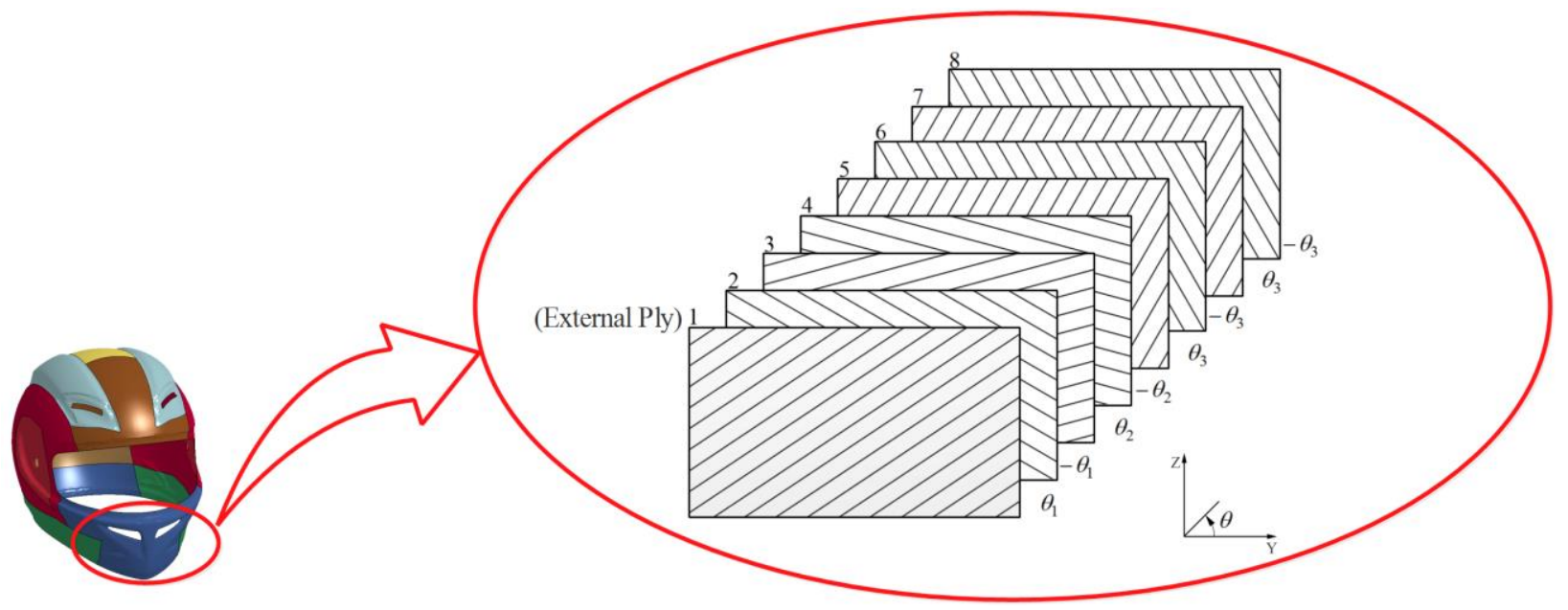

Figure 4 The chin bar ply lay-up. 
Table 3 Material properties of the shell used for FE simulations [44].

\begin{tabular}{llllll}
\hline & $\begin{array}{l}\text { Unidirectional } \\
\text { Glass/Epoxy }\end{array}$ & $\begin{array}{l}\text { Twill Weave } \\
\text { Glass/Epoxy }\end{array}$ & $\begin{array}{l}\text { Plain Weave } \\
\text { Glass/Epoxy }\end{array}$ & $\begin{array}{l}\text { Unidirectional } \\
\text { Carbon/Epoxy }\end{array}$ & $\begin{array}{l}\text { Unidirectional Hybrid } \\
\text { (Carbon/Kevlar)/Epoxy }\end{array}$ \\
\hline$\rho\left(\mathrm{kg} / \mathrm{m}^{3}\right)$ & 1984 & 1950 & 1266 & 1455 & 1400 \\
$E_{L}(\mathrm{GPa})$ & 46 & 29 & 34 & 174 & 110 \\
$E_{T}(\mathrm{GPa})$ & 16 & 29 & 8 & 9 & 8 \\
$G_{L T}(\mathrm{GPa})$ & 5.8 & 4.1 & 1.8 & 3.9 & 2.8 \\
$v_{L T}$ & 0.28 & 0.14 & 0.37 & 0.29 & 0.33 \\
$S_{u t, L}(\mathrm{MPa})$ & 1280 & 550 & 840 & 2000 & 1530 \\
$\varepsilon_{u t, L}(\mathrm{MPa})$ & 0.028 & 0.019 & 0.026 & 0.014 & 0.014 \\
$S_{u c, L}(\mathrm{MPa})$ & 800 & 490 & 126 & 1420 & 720 \\
$\varepsilon_{u c, L}$ & 0.018 & 0.017 & 0.02 & 0.01 & 0.008 \\
$S_{u t, T}(\mathrm{MPa})$ & 40 & 550 & 52 & 42 & 30 \\
$\varepsilon_{u t, T}$ & 0.025 & 0.019 & 0.014 & 0.009 & 0.004 \\
$S_{u c, T}(\mathrm{MPa})$ & 145 & 490 & 130 & 130 & 130 \\
$\varepsilon_{u c, T}$ & 0.012 & 0.017 & 0.016 & 0.014 & 0.015 \\
$\tau_{u}(\mathrm{MPa})$ & 73 & 80 & 60 & 60 & 60 \\
$\gamma_{u}$ & 0.04 & 0.04 & 0.051 & 0.051 & 0.051 \\
\hline
\end{tabular}

\subsection{Head-neck FE model}

It is common and computationally cost-effective to use isolated head-neck models to study head and neck injuries [54,55]. In the present work, the finite element model of the head-neck assembly of the Hybrid III $50^{\text {th }}$ percentile male dummy was used. This model was provided by Livermore Software Technology Corporation (www.Istc.com) and it has been validated for the neck extension calibration test [56]. Although the neck of the Hybrid III dummy shows a stiffer response than the human neck under direct head loading, particularly axial loading [57], it is widely used by researchers for testing helmets due to its robustness and the availability of its physical models. High fidelity computational models of the human neck have been used previously but a challenge with these models is that they do not have a physical counterpart, limiting their application for testing protective equipment.

\subsection{Impact conditions and the search algorithm}

Impacts during accidents can occur in many different conditions but standards have to prescribe a few more likely impact conditions for testing helmets. For the chin bar impacts using the head/neck assembly, we adopted the impact conditions prescribed in the Snell standard [42]. A $5 \mathrm{~kg}$ cylindrical impactor with an initial speed of $3.5 \mathrm{~m} / \mathrm{s}$ hit the chin bar of the helmet positioned on the Hybrid III head-neck (Figure 5). The neck bracket of the dummy was fixed as suggested in $[54,55]$. During simulations, the neck axial force was recorded.

To find a ply lay-up that transmits the minimum axial force to the neck, $\theta_{1}, \theta_{2}$ and $\theta_{3}$ were varied from zero to 90 degrees with an interval of 15 degrees. By considering this variation as a permutation problem with repetition, $7^{3}(=343)$ possible lay-ups had to be searched for the minimal neck axial force. A MATLAB code was developed to change the angles, modify and run LS-Dyna input files, store the maximum neck axial force during the impact as the output and generate a dataset of ply lay-up $\left(\theta_{1}, \theta_{2}\right.$ and $\left.\theta_{3}\right)$ versus 
neck axial force. After running all simulations for the entire design space, the code sorted the dataset from the minimum to the maximum value of the neck axial force (Figure 5).

In order to ensure that the helmet with an optimal ply lay-up for the chin bar can also pass the standard chin bar impact test, the ECE 22.05 standard test [41] was simulated. The helmet positioned on the FE model of the ISO headform was propelled towards a rigid anvil at a $5.5 \mathrm{~m} / \mathrm{s}$ speed (Figure 5). The MATLAB code started from the ply configuration that induced the minimum neck axial force, read the ply configuration and modified the LS-Dyna input file of the ECE virtual test. After running the simulation, the code filtered head accelerations using a butterworth filter [58] and calculated the Head Injury Criterion (HIC) and Peak Linear Acceleration (PLA). The code continued checking the configurations from the sorted dataset in order to find the one which passed the requirements of the ECE 22.05 standard, i.e. HIC $<2400$ and PLA $<275$ g.

Figure 5 shows the flowchart of the search algorithm. The entire simulations lasted 221 hours using a PC with an Intel Core $173.6 \mathrm{GHZ}$ processor and $32 \mathrm{~GB}$ RAM. All the simulations terminated correctly with no convergence or stability problems. 


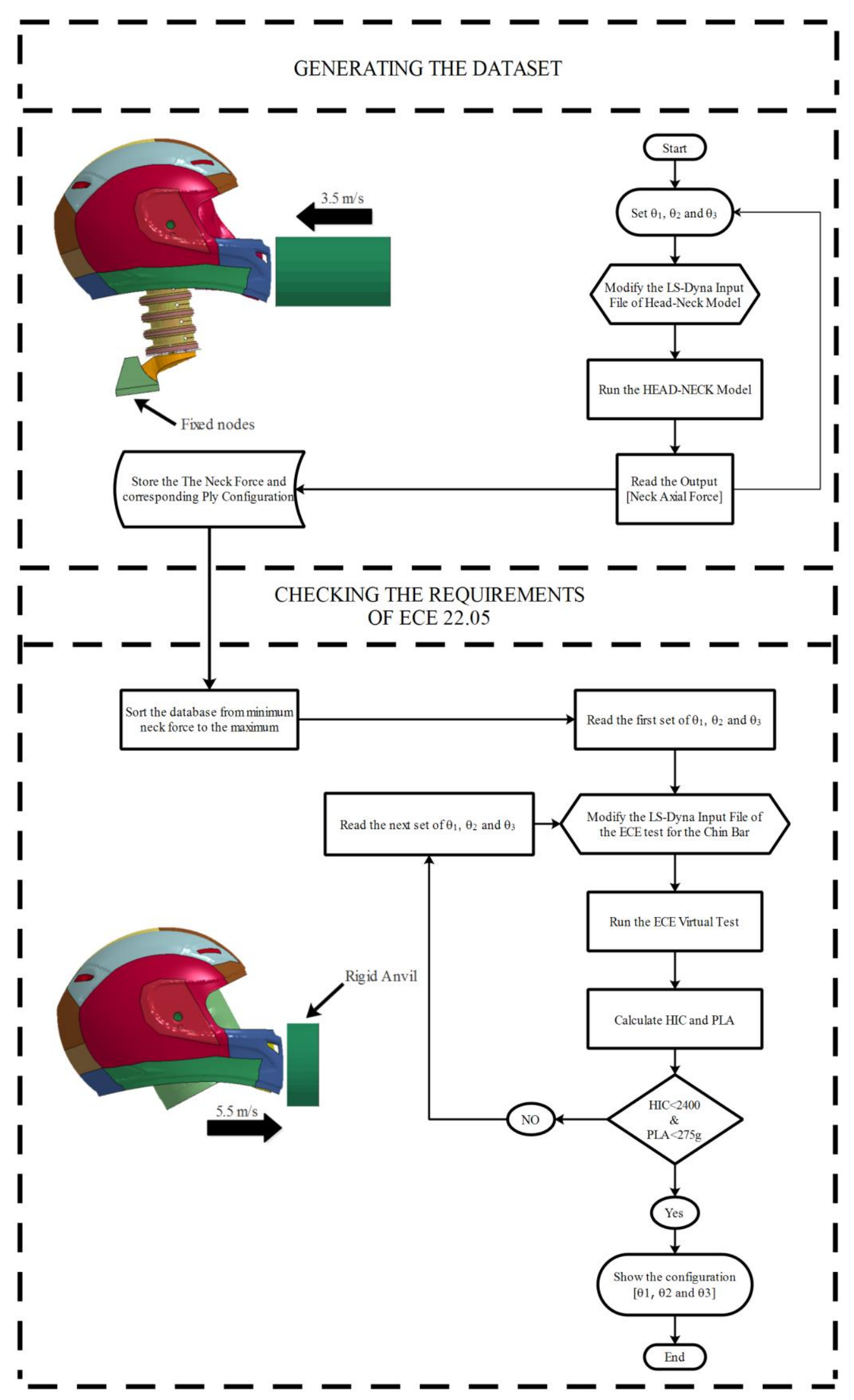

Figure 5 Flowchart of the search algorithm. 


\section{Results and Discussion}

We simulated the first 20 ms of the impacts. In all simulations, the peak neck force occurred during the first $15 \mathrm{~ms}$ of the impact. As can be seen in Figure 6, the impact deforms the chin bar shell and foam and reduces the distance between the chin liner and the chin. The chin liner did not touch the chin in any of the simulations using head/neck assembly. Instead, the chin strap transmitted the impact force from the helmet shell to the chin, leading to a large neck tensile force (Figure 7).

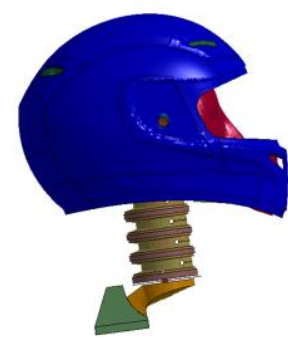

$\mathrm{t}=0 \mathrm{~ms}$

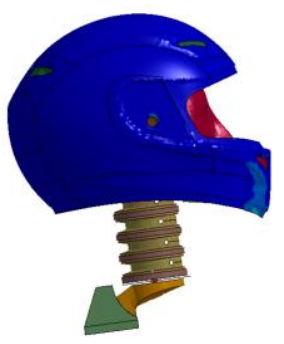

$\mathrm{t}=5 \mathrm{~ms}$

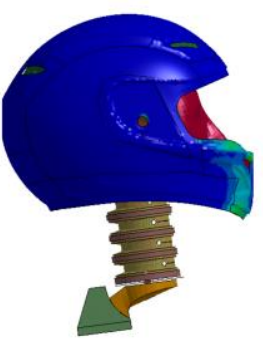

$\mathrm{t}=10 \mathrm{~ms}$

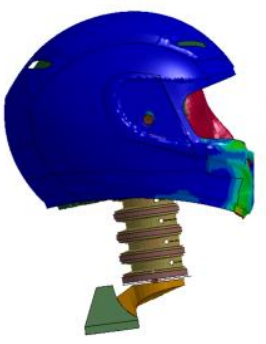

$\mathrm{t}=15 \mathrm{~ms}$

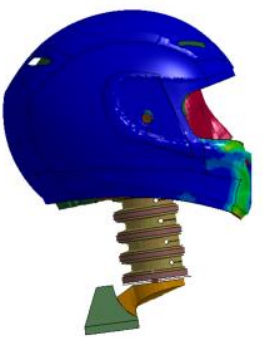

$\mathrm{t}=20 \mathrm{~ms}$

(a)

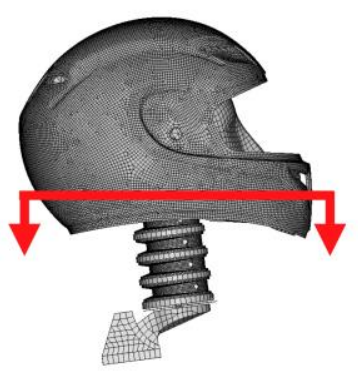

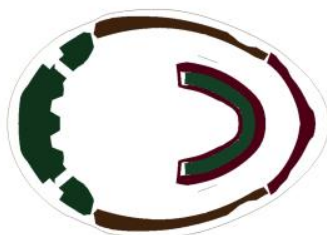

A-A: $\mathrm{t}=0 \mathrm{~ms}$

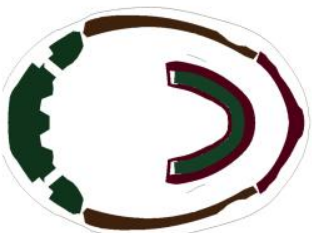

A-A: $\mathrm{t}=5 \mathrm{~ms}$

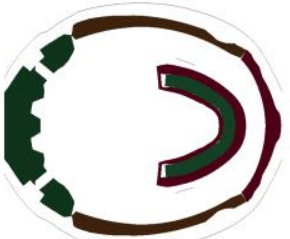

A-A: $\mathrm{t}=10 \mathrm{~ms}$

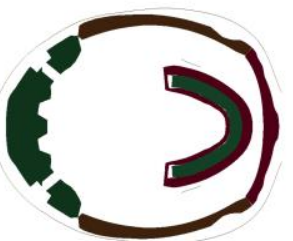

A-A: $\mathrm{t}=15 \mathrm{~ms}$

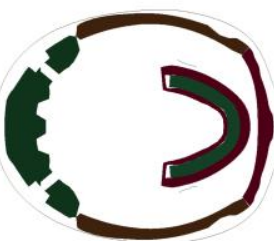

A-A: $\mathrm{t}=20 \mathrm{~ms}$

(b)

Figure 6 a. Deformation of the helmet chin bar at different time points (some parts of the helmet are not shown). b. Sectional view of the helmet, showing the deformation of the chin bar (both shell and liner) at different time points. 

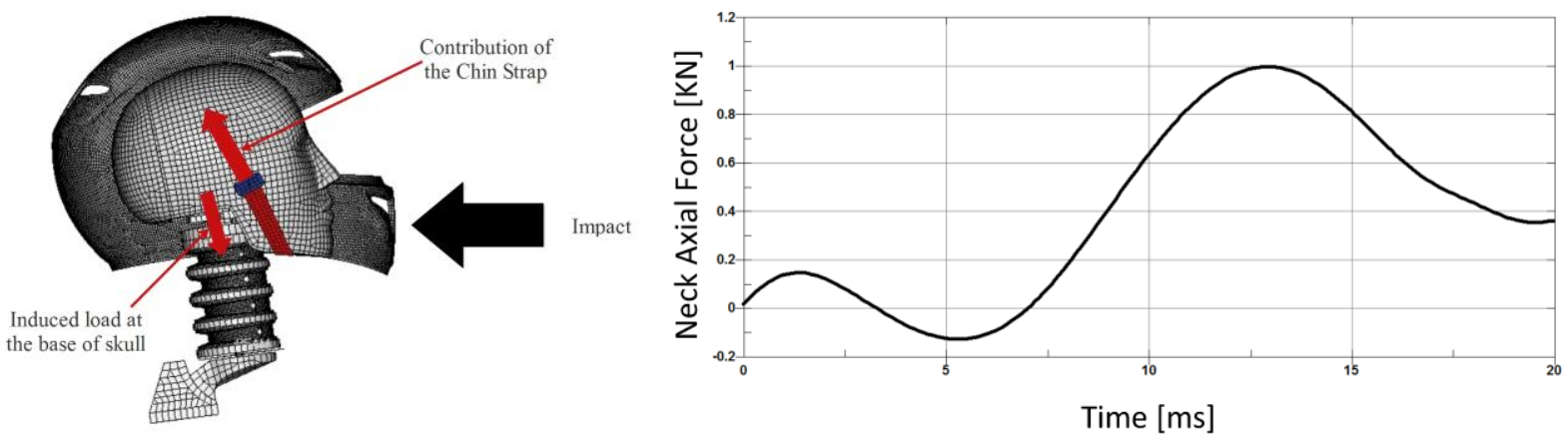

Figure 7 Right: The load transmission mechanism in a chin bar impact, (some parts of the helmet are not shown); Left: Neck axial load which was induced due to facial impact on the helmet chin bar.

The peak value of the predicted neck force in the dummy varied between $0.712 \mathrm{kN}$ and $1.037 \mathrm{kN}$, with a $0.928 \mathrm{kN}$ mean and a $0.060 \mathrm{kN}$ standard deviation. For all cases the largest neck force was tensile. We used multiple linear regression analysis to test how changing the angles influence the predicted neck force. The adjusted $R^{2}$ was 0.13 showing large variability but the F-test showed a significant linear trend $(F=18, p<0.001)$. The analysis results for the influence of each ply angle show that both $\theta_{2}$ and $\theta_{3}$ have significant influence on the neck force in the dummy ( $p<0.001$ for both) but the influence of $\theta_{1}$ was not significant $(p>0.9)$, probably because $\theta_{1}$ is the angle of the twill weave plies, which have the same properties in longitudinal and transverse directions (Table 3 ).

The predicted peak neck axial force versus ply angles are shown in Figure 8 for all 343 chin bar impact simulations. Figure $8(\mathrm{a})$ shows that the ply configurations with $\theta_{1}, \theta_{2}$ and $\theta_{3}$ equal to $0^{\circ}$ or $90^{\circ}$ induce the lowest neck axial forces. According to Figure $8(\mathrm{~b})$, there is also a local minimum when $\theta_{1}, \theta_{2}$ and $\theta_{3}$ are equal to $45^{\circ}$. The minimum neck force, $711.5 \mathrm{~N}$, was predicted for the $\left[(0)_{2},(90)_{2},(90)_{4}\right]$ chin bar laminate, but this helmet did not pass the ECE 22.05 test because the predicted HIC and PLA for the standard chin bar test were 1218 and $335 \mathrm{~g}$ respectively, with PLA being greater than its limit set in the standard. The first helmet with the lowest neck force $(724 \mathrm{~N})$ that passed the standard chin bar test with $\mathrm{HIC}=850$ and PLA $=272$ had a $\left[(0)_{2},(90)_{2},(0)_{4}\right]$ chin bar lay-up. Hereafter we call this configuration the optimum ply layup or optimum ply configuration. The chin bar with a $\left[ \pm 75, \pm 60,( \pm 15)_{2}\right]$ lay-up induced the maximum neck force $(1037 \mathrm{~N})$, but it passed the standard chin bar test with HIC $=479.1$ and PLA $=125.5$. This analysis shows that by only changing the ply angles of the chin bar laminate, thus keeping the mass of the helmet constant, the neck force can be reduced by $30 \%$ while still meeting the requirement of the standard. 


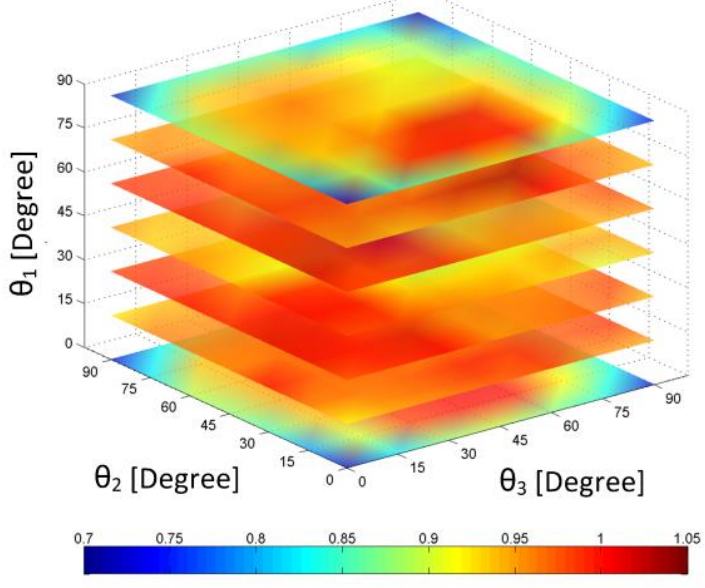

(a)

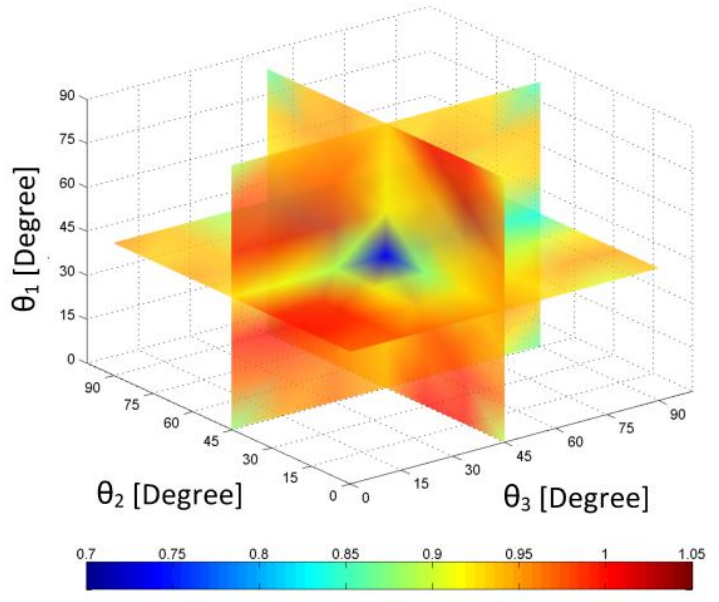

(b)

Figure 8 Iso surface plot of Neck Axial Force: a. Slice surface at $\theta_{1}=0, \theta_{1}=15, \theta_{1}=30, \theta_{1}=45, \theta_{1}=60, \theta_{1}=75, \theta_{1}=90$. b. Slice surface at $\theta_{1}=45^{\circ}, \theta_{2}=45^{\circ}, \theta_{3}=45^{\circ}$

The deformation of the chin bar shell under impact loading led to damage propagation in its layers, a mechanism for energy absorption and subsequent reduction of the neck force. Figure 9 shows the damage distribution in different plies of the chin bar that induced the highest neck force and the optimised chin bar. As can be seen, for the optimal lay-up, damage is better distributed between plies and it is spread across a wider area in each ply. As a result, the optimized chin bar absorbs more energy during the impact leading to a lower neck force. We determined the absorbed energy from the FE simulations by measuring the internal energy of the chin bar after the impact. The energy absorbed by the chin bar shell with the optimum lay-up was $9.2 \mathrm{~J}$, which was $40 \%$ larger than the energy absorbed by the stiffest chin bar shell, confirming that energy absorption during impact is a key to the reduction of the neck force.

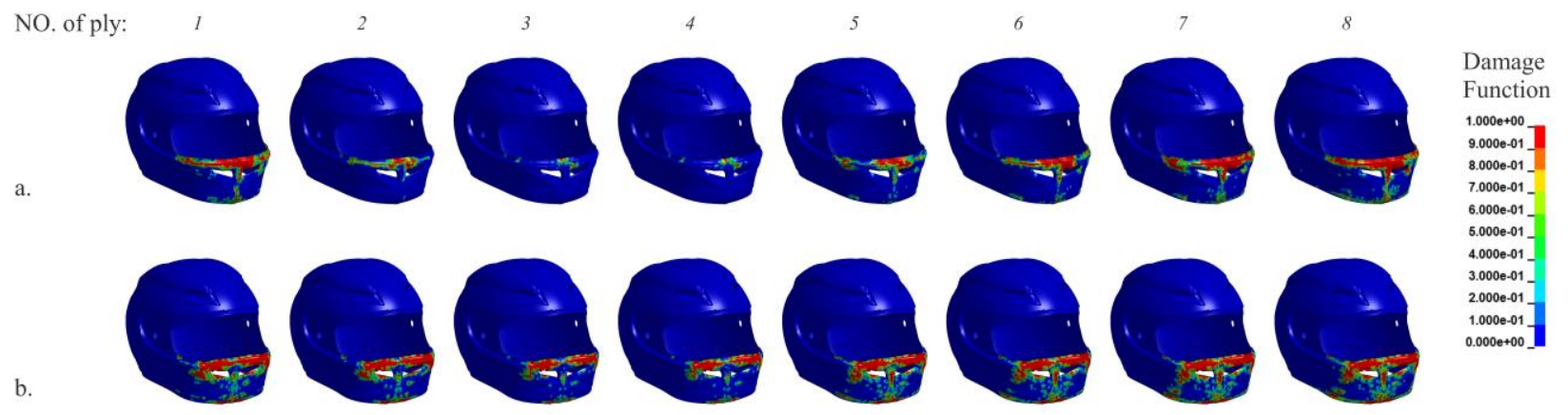

Figure 9 Damage distribution in the shell of the helmet in different plies. a. china bar, which induced the maximum neck load, $1037 \mathrm{~N}$, b. optimum chin bar, which induced $724 \mathrm{~N}$ of neck tensile load. 
Basilar skull fracture can take place in direct or indirect impacts, such as pedestrians accidents, falls and vehicle accidents [59], where the base of the skull is exposed to complex loading conditions that can cause BSF [60], but the mandibular loading with conjunction of neck tensile load, a common loading condition during motorcycle accidents [22], has the highest risk of basilar skull fracture [40]. In the present work we focused on the optimization of the helmet chin bar and introduced a numerical approach to optimize the stiffness of the chin bar laminate, which is correlated to the transmitted neck load due to the blow on the chin bar [27], in order to minimize the upper neck force due to such an impact.

Our results show that the neck axial force in the Hybrid III dummy reduces by reducing the stiffness of the chin bar laminate, but the chin bar stiffness reduction may increase the value of HIC and PLA during the ECE test. This is due to the further compression of the chin liner, producing larger force on the isolated headform thus increasing PLA. This effect can be compensated by including the chin liner in the optimisation [61], which is out of the scope of the present work. The focus of this work is on testing whether the chin bar design can be improved to mitigate the neck force, while ensuring that the requirements of standards are met.

One of the limitations of this work is using the Hybrid III head/neck system. Using a neck was necessary to measure the neck tensile force, the indicator of BSF, but the Hybrid III neck is known for its low fidelity particularly under head axial loading $[62,63]$. However this is not the load condition of interest in the present paper. Previous work has shown that as the angle between the neck axis and the loading direction approaches ninety degrees, the performance of the Hybrid III neck converges to the performance of a high fidelity computational model of the human neck, THUMS [44]. The Hybrid III dummy has been designed for car frontal impact tests and it has best fidelity for impacts in the sagittal plane, the same where the chin bar impacts simulated in this study take place. A direction for future work will be to use higher fidelity neck models to test the protection that different chin bar designs offer with respect to basilar skull fracture.

\section{Conclusions}

We presented possible improvements in chin bar design procedures. We used a computational approach to optimize the ply orientation of a composite chin bar to reduce the neck force, a parameter linked to basilar skull fracture in real accidents, while satisfying the requirements of the ECE22.05 standard. The optimal chin bar ply configuration reduced the neck axial force by $30 \%$ compared to the chin bar configuration that led to the maximum neck axial force, with the key protection mechanism being more energy absorption due to larger damage distributed within the plies of the chin bar laminate, while still satisfying the standard requirements. Our results show that the design of helmets can yet be improved to protect motorcyclists against different types of head injuries, without compromising their capability to meet current requirements of standards. This can be achieved by adopting computational approaches to provide the possibility of including different biomechanical criteria in the design process and reducing the design cost by decreasing the number of experimental iterations. This approach can be adopted by helmet manufacturers to improve their products, while they are waiting for new helmet testing standards.

\section{Acknowledgement}

The research leading to these results has received funding from the People Programme (Marie Sklodowska Curie Actions) of the European Union's Seventh Framework Programme FP7/2007-2013/ under REA grant agreement $n^{\circ}$ [FP7-PEOPLE-2013-ITN-608092]. 


\section{References}

[1] C. Brandstaetter, G. Yannis, P. Evgenikos, E. Argyropoulou, P. Papantoniou, M. Reurings, M. Vis, J. BROUGHTON, J. Knowles, J.-F. Pace, E. López-de-Cozar, P. Pérez-Fuster, J. Sanmartín, M. Haddak, Annual Statistical Report, Deliverable D3.9 of the EC FP7 project DaCoTA, 2012.

[2] M. KOORNSTRA, J. BROUGHTON, R. ESBERGER, C. GLANSDORP, W. KÖPPEL, F. TAYLOR, J.-P. CAUZARD, A. EVANS, L. HANTULA, M. PIERS, W. VANLAAR, TRANSPORT SAFETY PERFORMANCE IN THE EU A STATISTICAL OVERVIEW, Brussels, 2003.

[3] M. Peden, R. Scurfield, D. Sleet, D. Mohan, A. A. Hyder, E. Jarawan, C. Mathers, World report on road traffic injury prevention, Geneva, n.d.

[4] M.-R. Lin, J.F. Kraus, Methodological issues in motorcycle injury epidemiology., Accid. Anal. Prev.

[5] F.A.O. Fernandes, R.J. Alves de Sousa, Motorcycle helmets-A state of the art review, Accid. Anal.

[6] K.P. Krantz, Head and neck injuries to motorcycle and moped riders-with special regard to the effect of protective helmets., Injury. 16 (1985) 253-8.

[7] R. Ramli, J. Oxley, F.M. Noor, N.K. Abdullah, M.S. Mahmood, A.K. Tajuddin, R. McClure, Fatal injuries among motorcyclists in Klang Valley, Malaysia, J. Forensic Leg. Med. 26 (2014) 39-45.

[8] G. Badiali, E. Pasquini, O. Piccin, C. Marchetti, Injury risk related to the helmet strap: Mandible and hyoid bone fractures with a hyoepiglottic ligament lesion, 2010.

[9] J. V Ouellet, D.R. Thom, T. Smith, H.H. Hurt, HELMETS AND NECK INJURIES IN FATAL MOTORCYCLE CRASHES, in: Int. Mot. Saf. Conf., Orange County, US, 2013.

[10] M. Richter, D. Otte, U. Lehmann, B. Chinn, E. Schuller, D. Doyle, K. Sturrock, C. Krettek, Head injury mechanisms in helmet-protected motorcyclists: prospective multicenter study., J. Trauma. 51 (2001) 949-58.

[11] B.C. Liu, R. Ivers, R. Norton, S. Boufous, S. Blows, S.K. Lo, Helmets for preventing injury in motorcycle riders., 2008.

[12] A.K. Abbas, A.F. Hefny, F.M. Abu-Zidan, Does wearing helmets reduce motorcycle-related death? A global evaluation., Accid. Anal. Prev. 49 (2012) 249-52.

[13] F.M. Shuaeib, A.M.S. Hamouda, R.S.R. Umar, M.M. Hamdan, M.S.J. Hashmi, Motorcycle helmet Part I. Biomechanics and computational issues, J. Mater. Process. Tech. 3 (2002) 406-421.

[14] D. Sahoo, C. Deck, R. Willinger, Development and validation of an advanced anisotropic viscohyperelastic human brain FE model, J. Mech. Behav. Biomed. Mater. 33 (2014) 24-42.

[15] R. Willinger, C. Deck, Model Based Head Injury Criteria for Head Protection Optimization, in: Helmet Perform. Des., London, 2013.

[16] A. Cernicchi, U. Galvanetto, L. Iannucci, Virtual modelling of safety helmets: practical problems, Int. J. Crashworthiness. 13 (2008) 451-467.

[17] P.K. Pinnoji, P. Mahajan, Analysis of impact-induced damage and delamination in the composite shell of a helmet, Mater. Des. 31 (2010) 3716-3723.

[18] N.J. Mills, S. Wilkes, S. Derler, A. Flisch, FEA of oblique impact tests on a motorcycle helmet, Int. J. 
Impact Eng. 36 (2009) 913-925.

[19] M. Ghajari, U. Galvanetto, L. Iannucci, R. Willinger, Influence of the body on the response of the helmeted head during impact, Int. J. Crashworthiness. 16 (2011) 285-295.

[20] G.D. Caserta, L. Iannucci, U. Galvanetto, Shock absorption performance of a motorbike helmet with honeycomb reinforced liner, Compos. Struct. 93 (2011) 2748-2759.

[21] R.M. Coelho, R.J. Alves de Sousa, F.A.O. Fernandes, F. Teixeira-Dias, New composite liners for energy absorption purposes, Mater. Des. 43 (2013) 384-392.

[22] B. DOWDELL, G.J. Long, J. Ward, M. GRIFFITHS, A Study of helmet damage and rider head/neck injuries for crash involved motorcyclists, Roads and Traffic Authority, Road Safety Bureau, New South Wales Australia, 1988.

[23] T. Whyte, T. Gibson, R. Anderson, D. Eager, B. Milthorpe, Mechanisms of Head and Neck Injuries Sustained by Helmeted Motorcyclists in Fatal Real-World Crashes: Analysis of 47 In-Depth Cases., J. Neurotrauma. (2016).

[24] S. Piantini, M. Pierini, M. Delogu, N. Baldanzini, A. Franci, M. Mangini, A. Peris, Injury Analysis of Powered Two-Wheeler versus Other-Vehicle Urban Accidents, in: IRCOBI Conf., Malaga, Spain, 2016.

[25] C.P. Chee, A. Ali, Basal skull fractures. A prospective study of 100 consecutive admissions., Aust. N. Z. J. Surg. 61 (1991) 597-602. http://www.ncbi.nlm.nih.gov/pubmed/1867613 (accessed June 14, 2016).

[26] L.B. Rawling, The Surgery of the Skull and Brain, Oxford Medical Publication, London, 1912.

[27] T.J. Gibson, K. Thai, Helmet protection against basilar skull fracture, Australian Transport Safety Bureau, Canberra, 2007.

[28] A.A. Wani, A.U. Ramzan, T. Raina, N.K. Malik, F.A. Nizami, A. Qayoom, G. Singh, Skull base fractures: An institutional experience with review of literature, Indian J. Neurotrauma. 10 (2013) 120-126.

[29] F.H. Harvey, A.M. Jones, \&quot;Typical\&quot; basal skull fracture of both petrous bones: an unreliable indicator of head impact site., J. Forensic Sci. 25 (1980) 280-6.

[30] R.D. COOTER, D.J. DAVID, Motorcyclist Craniofacial Injury Patterns, in: Proc. Int. Mot. Saf. Conf., Orlando, 1990.

[31] L.E. Thibault, T.A. Gennarelli, Biomechanics and Craniocerebral Trauma, Central Nervous System Trauma Research Status Report, Bethesda, 1985.

[32] M.J. Shkrum, D.A. Ramsay, Forensic Pathology of Trauma, Humana Press, 2007.

[33] C.M. Shaw, E.C. Alvord, Injury of the basilar artery associated with closed head trauma., J. Neurol. Neurosurg. Psychiatry. 35 (1972) 247-57.

[34] S. Sprogøe-Jakobsen, E. Falk, Fatal thrombosis of the basilar artery due to a minor head injury., Forensic Sci. Int. 45 (1990) 239-45.

[35] E. Shaqiri, G. Vyshka, A. Sinamati, B. Ymaj, Z. Ismaili, Fatal basilar thrombosis possibly related to minor cervical trauma: a case report., Case Rep. Med. 2010 (2010). 
[36] E.R. LeCOUNT, J. Hockzema, Symmetrical traumatic fractures of the cranium; symmetrical fragmentation, Arch. Surg. 29 (1934) 171.

[37] B.M. VANCE, E.R.. and A.C.W. LeCount, C.W. Apfelbach, Fractures of the skull, Arch. Surg. 14 (1927) 1023.

[38] A.R. Moritz, The pathology of trauma, Henry Kimpton, London, 1954.

[39] S. WERNE, Studies in spontaneous atlas dislocation., Acta Orthop. Scand. Suppl. 23 (1957) 1-150.

[40] J.H. McElhaney, R.H. Hopper, R.W. Nightingale, B.S. Myers, Mechanisms of basilar skull fracture., J. Neurotrauma.

[41] ECE 22.05, Uniform Provisions Concerning the Approval of Protective Helmets and of their Visors for Drivers and Passengers of Motorcycles and Mopeds, E/ECE/324 \& E/ECE/TRANS/505 Addendum 21, Regulation No. 22, Revision 4, Geneva, 2002.

[42] Snell 2015, STANDARD FOR PROTECTIVE HEADGEAR For Use with Motorcycles and Other Motorized Vehicles, 2015.

[43] M. Ghajari, C. Deck, U. Galvanetto, L. lannucci, R. Willinger, Development of numerical models for the investigation of motorcyclists accidents, in: 7th Eur. LS-Dyna Conf., 2009.

[44] M. Ghajari, The Influence of the Body on the Response of the Helmeted Head during Impact, Imperial College London, 2011.

[45] LS-Dyna Keyword User's Manual, 2014.

[46] L.J. Gibson, M.F. Ashby, Cellular Solids, Structure and Properties, 2nd ed., Cambridge Solid State Science Series, 1999.

[47] M. Ghajari, S. Peldschus, U. Galvanetto, L. Iannucci, Evaluation of the effective mass of the body for helmet impacts, Int. J. Crashworthiness. 16 (2011) 621-631.

[48] A. Matzenmiller, J. Lubliner, R.L. Taylor, A constitutive model for anisotropic damage in fibercomposites, Mech. Mater. 20 (1995) 125-152.

[49] X. Xiao, M.E. Botkin, N.L. Johnson, Axial crush simulation of braided carbon tubes using MAT58 in LS-DYNA, Thin-Walled Struct. 47 (2009) 740-749.

[50] K. Schweizerhof, K. Weimar, T. Munz, T. Rottner, Crashworthiness analysis with enhanced composite material models in LS-DYNA-merit and limits, in: Fifth Int. LS-DYNA Conf., Southfield, Michigan, 1998.

[51] M. Ghajari, S. Peldschus, U. Galvanetto, L. Iannucci, Effects of the presence of the body in helmet oblique impacts., Accid. Anal. Prev. 50 (2013) 263-71.

[52] H.W. Wang, H.W. Zhou, L.L. Gui, H.W. Ji, X.C. Zhang, Analysis of effect of fiber orientation on Young's modulus for unidirectional fiber reinforced composites, Compos. Part B Eng. 56 (2014) 733-739.

[53] E. Mahdi, A.M.S. Hamouda, T.A. Sebaey, The effect of fiber orientation on the energy absorption capability of axially crushed composite tubes, 2014.

[54] J.C. Roberts, T.P. Harrigan, E.E. Ward, T.M. Taylor, M.S. Annett, A.C. Merkle, Human head-neck 
computational model for assessing blast injury, J. Biomech. 45 (2012) 2899-2906.

[55] K.M. Tse, L. Bin Tan, S.J. Lee, S.P. Lim, H.P. Lee, Investigation of the relationship between facial injuries and traumatic brain injuries using a realistic subject-specific finite element head model, Accid. Anal. Prev. 79 (2015) 13-32.

[56] S. Guha, LSTC_NCAC Hybrid III 50th Dummy Positioning \& Post-Processing, 2014.

[57] A. Bartsch, E. Benzel, V. Miele, D. Morr, V. Prakash, Hybrid III anthropomorphic test device (ATD) response to head impacts and potential implications for athletic headgear testing., Accid. Anal. Prev. 48 (2012) 285-91.

[58] SAE J211-1 (1995): Instrumentation for Impact Test, Part 1, Electronic Instrumentation, 2007.

[59] M. Liu-Shindo, D.B. Hawkins, Basilar skull fractures in children., Int. J. Pediatr. Otorhinolaryngol. 17 (1989) 109-17.

[60] G.E. Voigt, G. Sköld, Ring fractures of the base of the skull., J. Trauma. 14 (1974) 494-505.

[61] C.H. Chang, L.T. Chang, G.L. Chang, S.C. Huang, C.H. Wang, Head injury in facial impact--a finite element analysis of helmet chin bar performance., J. Biomech. Eng. 122 (2000) 640-6.

[62] B. Fréchède, A. McIntosh, R. Grzebieta, M. Bambach, Hybrid III ATD in inverted impacts: influence of impact angle on neck injury risk assessment., Ann. Biomed. Eng. 37 (2009) 1403-14.

[63] B. Herbst, S. Forrest, D. Chng, A. Sances, Fidelity of Anthropometric test dummy necks in rollover accidents, in: Proc. 16th Int. Tech. Conf. Enhanc. Saf. Veh., Washington, 1998. 